\title{
Acceptance Model Of E-Flipped Learning for Students in Jordan Schools
}

\author{
Samar Mahmoud Mohammad Akho Zhayeh ,Chief Knowledge Officer, ASK for Human Capacity Building, \\ Company,Doctorofacademy@gmail.com
}

\begin{abstract}
E-Flipped learning is considered one of the modern instructional techniques that attempts to improve students' learning in Jordan. As any other techniques, the flipped learning has many positive aspects or/and advantages; however, users' adoption is still in the early phases and it is seen to be slow in many developing countries. This E-flipping learning is known as one of the pedagogical approaches, in this approach there is a conventional notion of classroom-based learning as it is inverted to deepen the understanding by using problem-solving activities and discussion with peers that are facilitated by teachers. Besides, little is observed regarding the perception and behavior of student toward the use of the e-flipped learning method, the author reviewed research on an acceptance model of e-flipped learning for students towards better educational achievements. Thus, the present research tries to explore the relationships between Effort Expectancy (EE), Social Influence (IS), Performance Expectancy (PE) and using the Unified Theory of Acceptance and Use of Technology (UTAUT) with focusing on the system characteristics to the intention as well as behavior of e-flipped learning use. To accomplish the main research objective, the structural equation model has been employed. In the Jordanian context, this model may help the system developer to develop a proper e-flipped learning that can be easily oriented for students. This study's results indicated that the factors of behavioral intention of using e-flipped learning positively affect students toward the acceptance of e-flipped learning.
\end{abstract}

Keywords: E-Flipped Learning, Social Influence, Performance Expectancy, System Characteristics, Effort Expectancy

\section{INTRODUCTION}

The advancement of technology can be considered the most influential indicator of the rapidity of change in our societies. This can be observed by the availability of many computers in most of the schools, workplaces, and houses providing the individuals by strong means of understanding and having massive information in the worldwide, with access and transmit through computers. Therefore, the development of technology may change the way that people live in their work, study environment, and their own daily life (Alawamreh \& Elias, 2015; Al-Rahmi et al., 2018).

The information growing with the increasingly use of computers attributed at the explosion with the need of experience and education field, for example, the environment of e-learning is a base in many educational institutions. Saving effort, time and even cost are seen to be some advantages of using e-learning (Jalal \& Mahmood, 2019). In daily learning processes, e-learning becomes important and improves the general learning processes of students. The old traditional ways of teaching had made more offers and interesting platform for learners and teachers (Cheok, Wong, Ayub, \& Mahmud, 2017).

Accordingly, it is seen that the e-flipped learning as a learning process is deemed to be a pedagogical approach. In fact, this approach was basically conventional classroom-based learning notion. It is currently inverted to mean that learners/students are being introduced to the material which is used for learning inside classrooms to deepen understanding through the use of discussion strategy with their peers by having some activities including problem solving and these activities are being facilitated by teachers (Sargent \& Casey, 2020).

In fact, students, when using traditional learning process, acquire knowledge in their classrooms contexts and then, they evaluated and synthesized that after class. In the case of the flipped classroom, it is seen to be different, because the students acquire knowledge before they come to their class and the time of the classroom is used for applying and practicing the information, ideas and concepts by the interaction 
between teachers and peers. Then due to the feedback which is received, students can use what they have learnt. The flipped classroom approach's users emphasize on the deep learning and they encourage and call for a higher level cognitive skills (Ahmed, 2016; Sargent \& Casey, 2020).

Due to the educational system has been moved to distance learning and e-learning during the lockdown period of COVID 19 pandemic, not only in Jordan but across the globe, this led to a several pedagogical strategies that can be used and one of them is e-flipped learning

\section{E-Flipped Learning}

The contemporary approaches of education are various, and flipped learning is one of these most known approaches which can be said to be originated from the Socrates' maieutic, in this approach, teachers help students to discover both knowledge as well as truth by guiding them by using debates and discussions that may not have complete solutions (Bognar, Sablić, \& Škugor, 2019). In 2007, the flipped learning was developed by Aaron Sams and Jonathan Bergmann who were high school teachers in Colorado School. More specifically, They started to record lectures, making slide presentations and videos to be posted on YouTube channels to let the students who did not attend classes to learn (Bergmann \& Sams, 2014). According Bognar et al. (2019), flipped learning is considered a new pedagogical method using practice problems and asynchronous video lectures as homework and activities to be practiced in their class such as the groupbased problem solving activities.

There are many educators give the importance of e-Learning, and they incorporate it in teaching strategies like e-flipped learning and that from practical perspective and conceptual perspective too. Thus, flipped classroom is seen to be reflecting the complementary approach in education. As for the e-flipped learning it is deemed to be a pedagogical approach where conventional notion regarding the classroombased learning is being inverted in order to obtain a deep understanding by using discussion with peers and the activities of problems- solving to be guided and facilitated online by teachers (Bognar et al., 2019; Zainuddin, 2018).

Although e-Flipped Classroom is common method includes making e-learning lectures and other elearning content open to students at anytime, anywhere, for access. In this way, teachers are able to shift their teaching position to the guide on the side, using e-flipped classroom to illustrate concepts, demonstrate strategies, concentrate on problem solving, and use dialogue with students and teachers to confront erroneous conceptualizations (King \& Piotrowski, 2015).

In Jordan, e-learning is not designed or developed to cope with the flipped learning. This makes the acceptance of the available e-learning systems to be evaluated in order to go along with the requirements of the new educational method (flipped learning) that students can learn through. For instance, it is suggested that the applications of e-learning should have more features to improve and enhance the education of the students (Alawamreh \& Elias, 2016; Almajali \& Al-Lozi, 2016; Kim \& Seo, 2009).

\section{The Unified Theory of Acceptance and Use of Technology (UTAUT)}

This theory explains technology acceptance as well as it consists of eight models or theories of technology acceptance. More precisely, the UTAUT is derived from models such as the Theory of Reasoned Action (TRA), the Technology Acceptance Model (TAM), the Motivational Model, the Personal Computer Utilization Model, combination of the Technology Acceptance Model (TAM) and the Theory of Planned Behavior (TPB), the Social Cognitive Theory, the Innovation Diffusion Theory (IDT), and the Technology Acceptance Model (TAM) (Venkatesh et al. 2003). Accordingly, the behavioral intention is used by the UTAUT model as technology use behaviors' predictor and the behavioral intentions are being based on the eight technology adoption models' components (Venkatesh et al. 2003).

There are different elements, in the model of UTAUT, such as Performance Expectancy (PE), social elements, and Effort Expectancy (EE) directly affect the behavioral intention and then directly affect behavior use. Additionally some other factors can be included e.g., the experience interactions, age, and gender with each of EE, PE, as well as some social elements. The facilitating conditions also directly affects the used behaviors, and the interaction of each of $\mathrm{PE}$, social elements on behavioral intention and an interaction of voluntariness of use. In addition, the interaction of the facilitating conditions and experience, and the facilitating conditions and age directly affect use behaviors (Thomas, Singh, \& Renville, 2020; Venkatesh et al. 2003). 


\section{Proposed Model of E-flipped learning for Students}

This part of the study describes the UTAUT model consisting of the following factors: SI, PE and EE (e.g., Venkatesh et al., 2003). Additionally a factor of system characteristics and the following subsection will describe each factor in the model in details:

\section{Proposed model of E-flipped learning for students Performance Expectancy (PE)}

PE is defined by Venkatesh et al. (2003: p.447) as "the degree to which the user expects that using the system will help him or her to attain gains in job performance". This means, when people believe that new technologies will help them to perform their job better, they are more probable adopting such technologies.

$\mathrm{PE}$ as a factor is seen to be similar to the perceived usefulness derived TAM and it is known of being one of the fundamental attributes to influence the attitudes of individual towards any system use. In addition, PE is also defined to be the level where an individual thinks that the use of certain biometric system may fulfil the security access requirements of an organization in any particular domains. Furthermore, the performance expectancy is found to significantly, uniquely, positively influence and significantly and the behavioural intension of technology use (e.g., Venkatesh et al.'s, 2003; Catherine, Geofrey, Moya, \& Aballo, 2018).Therefore, in this study PE refers to the degree where the user expects that using e-flipped learning can help her/him to obtain a good grade, productivity, usefulness and to accomplish tasks more quickly in students' performance.

\section{Effort Expectancy (EE)}

EE is defined to be the easiness level that is related in using any systems (Venkatesh et al., 2003) meaning that it is referred to the efforts required to employ the systems even it was complicated or simpler. Most users prefer technologies providing them ease of use, flexibility, the usefulness.

Interestingly, each individual model construct is seen to be important in mandatory as well as voluntary settings, and based on previous studies, it was only essential during the post training measurements. Furthermore, the EE impact on behavioural intentions is hypothesized to be moderated by experience, gender as well as age. Thus, the effect can be stronger at the early stages of experience for older workers as well as young women (e,g., Attuquayefio \& Addo, 2014; Jong \& Wang, 2009; Razak, Bakar, \& Abdullah, 2017).

Besides, previous studies indicated that EE significantly affects behavioural intentions to use elearning, mobile learning, management learning system etc (Al-Okaily, Lutfi, Alsaad, Taamneh, \& Alsyouf, 2020; alawamreh \& Elias, 2015). Thus, the researcher generated the most used factor as effort expectancy in domain related to e-flipped learning to be hypothesised. Therefore, in this study, the EE is being referred to the ease degree related to e-flipped learning use in some fields like understanding, ease of use and skilful at using e-flipped learning.

\section{Social Influence (SI)}

SI is known to be the degree where individuals have been affected by others to use the new systems that can be represented in various models such as TRA, Technology Acceptance Model 2 (TAM2), social elements in the Model of Personal Computer Utilization (MPCU), and the image in the IDT. The models are behaved similarly and they are significant when they mandatorily use, but in voluntary setting, they are insignificant. It is explained that, it is significant because of punishment or rewards. On the other hand, in the voluntary context, the social influences have perceptions about technology (equally known as the identification and internalization). Furthermore, it is proven by literature that each of experience, voluntaries, age and gender moderates the relationship between social influences on behavioral intentions. Such influence has stronger effects of women and especially in the early ages of experience (e.g., Attuquayefio \& Addo, 2014; Ifinedo, 2016; Jong \& Wang, 2009; Venkatesh et al., 2003).

The SI construct included in the UTAUT is adopted by the researcher in the present study. In fact, the SI is seen to be a behaviour or opinion that is affected by others (Vululleh, 2018). In the present study, SI is the extent where school learners perceive that their use of e- flipped learning is motivated by extended factors such as their peers, instructors and school.

\section{System characteristics}


The flexible access to the instructional e-flipped learning usage is supported by the perceived ability of the tools' system as being indicated by system characteristics. More deeply, some functions are carried out by such systems through the combination of various media types as text, audio or video, monitored by the learner and the software's system. Moreover, the system of e-flipped learning is designed and studied to help in accessing to the web anywhere and anytime to the content of the courses from remote or far locations. These characteristics make it critical for promoting and motivating the use of the web-based learning systems (Brown, 2002), also, competence, which today defines intrinsic motivation (Andujar, Salaberri-Ramiro, \& Cruz Martínez, 2020; Chen Hsieh, Wu, \& Marek, 2017; Shroff, Vogel, Coombes, \& Lee, 2007). In this study, system characteristics is indicated to the perceived capacity of a system resources to provide versatile, and engaging contact between teacher and students of usage the e-flipped learning.

\section{Behavioral Intention (BI)}

The person's perceived likelihood, and the subjective probability that the person has with a given behaviour are known as the BI (e.g., Cegarra, Navarro, \& Pachón, 2014; Yeo, Goh, \& Rezaei, 2017). Also, it is based on the relationship of planned behaviour theory (Taylor \& Todd, 1995).

It is seen that both the social norms and attitude are the cause of the intention. Based on previous studies a positive relationship is found between the intension of the behaviour and the actual behaviour use (Hameed \& Qayyum, 2018). The previous research examined different antecedents of system learning, user perspective of e-learning in the presence models of UTAUT, TAM as well as IS and theories to measure the influence on behavioural intentions and found significant effects (Hameed \& Qayyum, 2018; Wong, Wang, Ng, \& Kwan, 2015).

The BI is being a specific behaviour that is operationalized with straight questions, and Likert Scale responses choices can be used and that for measuring and testing the relative strong intension point, also, intension can be measured by using other synonyms e.g., "I intend to behaviour" can be replaced by a synonym as follows: "I plan to behaviour" (e.g., Armitage, Norman, \& Conner, 2002; Nikou \& Economides, 2017; Schaper \& Pervan, 2009). In this study, BI is defined as the perceived probability or subjective likelihood of a person that he or she intends to participate, predict, and expect to use e-flipped learning.

\section{Objective and Hypothesis}

The main aim of the present study is to identify the factors that affect the e-flipped learning acceptance of students to enhance their education. The elements that are discussed and examined in this study are consisting from: system characteristics, PE, EE and SI.

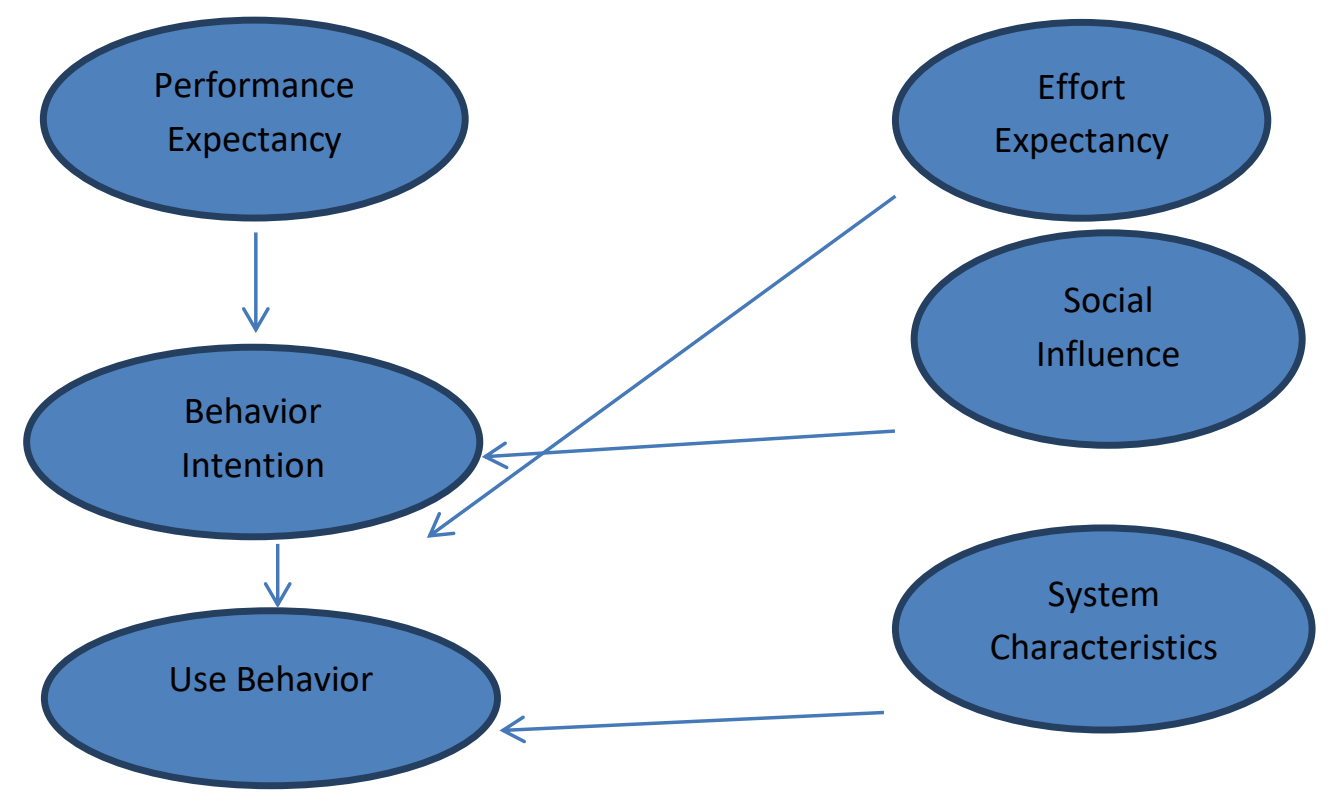

Figure 1. Proposed model of e-flipped learning for students 
This study examines four hypotheses, which are:

H1: The PE significantly affects behavioral intention

H2: The EE significantly affects behavioral intention

H3: The SI significantly affects behavioral intention

H4: System characteristics significantly affect the use behavior

H5: The behavioral intention significantly affects the use behavior

\section{METHODOLOGY}

\section{Research Design}

During the collection of data, the researcher used quantitative research techniques and a cross- sectional field survey as the design of the research. This allows the researchers to collect data from the random sample regarding the situations, practices or beliefs of the subjects by using survey questionnaires (Leavy, 2017). As well as, the questionnaires which were used were tested for validity and reliability before the survey.

\section{Population of the Study and Sample Size}

The population of this study included all $10^{\text {th }}$ grade students in Balqa' governorate in Jordan; there are 160 schools containing 4000 students according to the data obtained from the Ministry of Education in Jordan.

The sample selected 196 students for math subject in Balqa governate schools in Jordan. The sample size was selected based on the determination of the sample size formula presented by the table of Krejcie and Morgan (1970), accordingly, 230 questionnaires being collected from students. Out of this number, 15 were undelivered and 12 were incomplete (missing responses). Thus, a total of 203 responses were used for subsequent analysis, giving a response rate of $88 \%$.

The sample size was sufficient and the response rate obtained was comparable to several previous studies in the same area. According to Mugenda and Mugenda (2003), 50\% is adequate, $60 \%$ is good, and $70 \%$ and over is excellent.

\section{Sampling Procedures}

A simple random sampling process is used in this study for fulfilling its purpose. There are two stages of this process which are: selecting a number from each class randomly, and selecting a number of math subject randomly from every class until having the desired sample.

\section{Instruments of the Study}

There are different methods for the need assessment and collecting data e.g., focus group, on- site observations and interviews. These methods are used for providing information about a wide variety and a large number of respondents(Balogun, Huff, \& Johnson, 2003; Kelley, Clark, Brown, \& Sitzia, 2003). In this study, a questionnaire for determining the factors which have effects on the intension of using e-flipped learning, has been developed and the conceptual model of this study includes different instruments. E-flipped learning can enable students to increase their productivity grades and fulfil their jobs.

Moreover, the effort expectancy and performance expectancy indicate that e-flipped is easy to use, easy to learn, understandable and clear. While, the people who influence the students' behaviour to use eflipped learning is indicated by social influence. E-flipped learning system offers flexibility in learning and that is indicated by some system characteristics. Additionally, e-flipped learning systems help in the interactive communication between students and instructors.

\section{RESULT DISCUSSION}

\section{Validity}

The researchers conducted three categories of validity (convergent, construct, and discriminant).

\section{Convergent Validity}

Convergent validity could be verified by computing the Average Variance Extracted (AVE) for every construct (Awang, 2015). This validity is achieved when the AVE for the construct in the model exceeds 0.50 (Awang, 2015). The AVE values for PE, EE, SI, and SC were $0.579,0.536,0.580$, and 0.559 , respectively. 
As recommended by Awang (2015) and Hair et al. (2010), at least one of the three categories (absolute, incremental, and parsimonious) should be fit. For the absolute fit index (RMSEA $=0.072$, P-value $=0.000$ ), the value was acceptable because the RMSEA value was less than 0.08 and the P-value was less than 0.05 . Meanwhile, for the incremental fit index (CFI $=0.953$ ), the value exceeded 0.90, whereas for the parsimonious fit index (Chi-square/df = 2.439), it was less than 3 .

\section{Discriminant Validity}

Table 1. Discriminant Validity

\begin{tabular}{|l|l|l|l|l|l|l|}
\hline & $\begin{array}{l}\text { composite } \\
\text { Reliability } \\
\text { (CR) }\end{array}$ & $\begin{array}{l}\text { Average } \\
\text { Variance } \\
\text { Extracted } \\
\text { (AVE) }\end{array}$ & PE & EE & SI & SC \\
\hline PE & 0.712 & 0.579 & 0.761 & & & \\
\hline EE & 0.804 & 0.536 & 0.518 & 0.732 & & \\
\hline SI & 0.833 & 0.580 & 0.627 & 0.727 & 0.761 & \\
\hline SC & 0.778 & 0.559 & 0.348 & 0.534 & 0.553 & 0.747 \\
\hline
\end{tabular}

\section{Composite Reliability}

Each measure composite reliability is determined by the second test, as presented in (Table 1) and for evaluating unweaving quality coefficients by referring to the rule of (Nunnally, 1978). The unwavering composite quality relied on the institutionalized factor loading which acquired from the last updated estimation model demonstrating that all builds have a worthy estimation of more than 0.60 (Nunnally, 1978; Preston \& Colman, 2000).

\section{Hypothesis Testing of Generating Model}

The influence of an exogenous construct is represented by a direct effect. Figure 2 shows the hypothesis testing that aimed to determine the significance of each path coefficient, an estimate of the regression weight, standard error in the regression weight, and critical ratio for regression weight that was used.

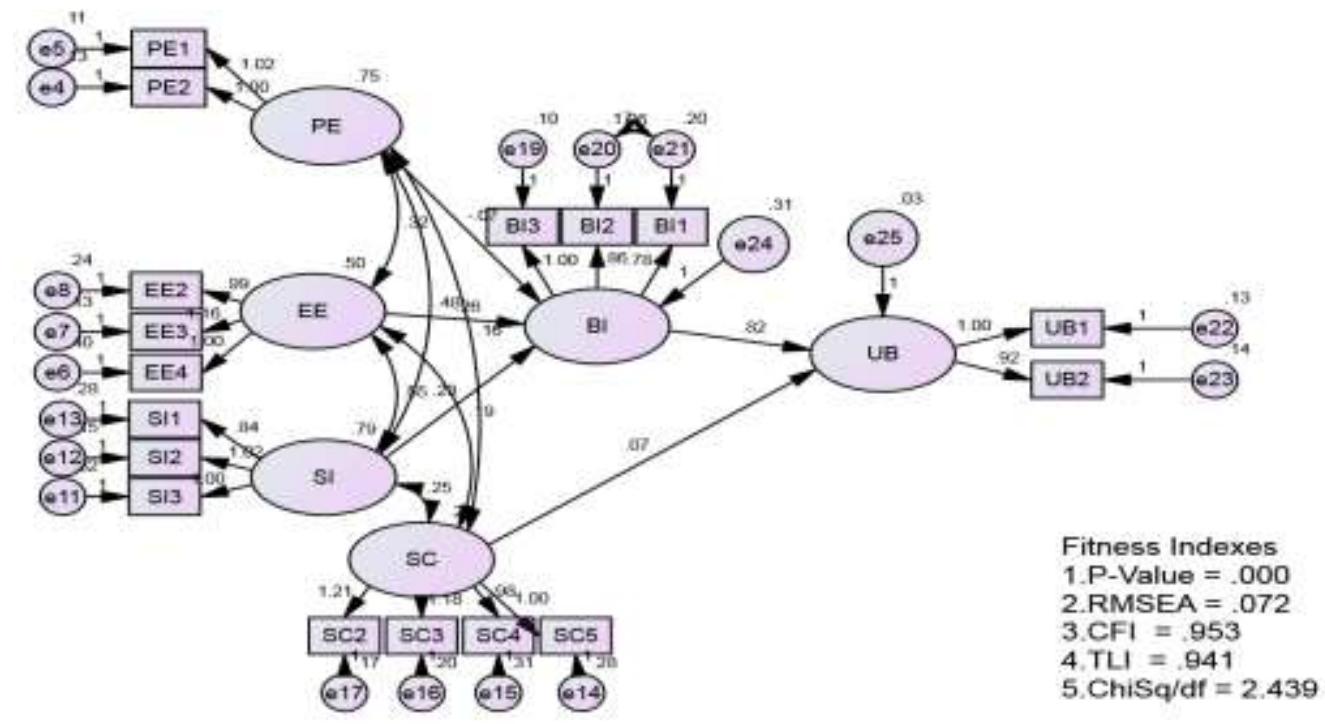

Figure 2. The Regression Path Coefficient 


\section{Hypothesis Testing}

The exogenous construct directly affect an endogenous construct. Figure 2 and Table 2 show the hypothesis testing that aimed to determine the significance of each path coefficient, an estimate of the regression weight, standard error in the regression weight, and critical ratio for regression weight that was used.

Table 2. direct effects

\begin{tabular}{|l|l|l|l|l|l|l|l|}
\hline Hypothesis & $\begin{array}{l}\text { Regression } \\
\text { weights } \\
\text { From }\end{array}$ & To & Estimate & $\begin{array}{l}\text { Standard } \\
\text { error }\end{array}$ & $\begin{array}{l}\text { Critical } \\
\text { ratio }\end{array}$ & $P$ & Result \\
\hline H1 & PE & BI & .070 & .060 & 1.164 & $* * *$ & significant \\
\hline H2 & EE & BI & .261 & .149 & 1.751 & 0.003 & Significant \\
\hline H3 & SI & BI & .232 & .131 & 1.773 & $* * *$ & Significant \\
\hline H4 & SC & UB & .073 & .051 & 1.416 & 0.041 & Significant \\
\hline
\end{tabular}

H1 intended to test the effect of PE on BI was found to have a significant positive and direct effect $(P=* * *)$; thus, $\mathrm{H} 1$ was supported.

$\mathrm{H} 2$ intended to test the effect of EE on BI was found to have a significant positive and direct effect $(P=0.003)$; thus, $\mathrm{H} 2$ was supported.

H3 intended to test the effect of SI on BI was found to have a significant positive and direct effect $\left(P={ }^{* * *}\right)$; thus, H3 was supported.

H4 intended to test the effect of SC on UB was found to have a significant positive and direct effect $(P=$ 0.041); thus, $\mathrm{H} 4$ was supported.

\section{DISCUSSION}

This part of the study showed the results and the details of the outcomes after analyzing the data. Also, the study showed the responses' rate, factor analysis, correlation analyses, hypotheses testing, reliability assessment, and descriptive analysis. The first analysis part entailed the testing of the assumptions of linearity, homoscedasticity, and normality. The outcomes generated and demonstrated that the assumptions were met generally. Also, factor analysis was conducted to testing the construct validity of all the interval scale variables. Additionally, a reliability analysis was achieved to confirm the reliability of the items in all constructs, or the accurateness of the measurement instrument that this study used. Accordingly, the results indicate that the instrument of this study is both reliable and suitable for the construct measurement.

The purpose for conducting applied research is to find solutions to improve practice; according to this purpose, present research adopted system characteristic to identify factors influencing acceptance of eflipped learning, social influence effort expectancy, system characteristic, and performance expectancy. In this respect, these variables were identified as factors influencing intent and behavior of users of e-flipped learning.

Results obtained from data analysis for $\mathrm{H} 1$ suggested a positive and significant effect of performance expectancy on the behavioral intention towards using e-flipped learning; thus if users feel that using e-flipped learning improves their performance, they are more motivated to use it. This result is consistent with that studies (Alawamreh \& Elias, 2016; Davis, Bagozzi, \& Warshaw, 1989; Venkatesh \& Davis, 2000).

Second result, within the other factors influencing acceptance of e-flipped, the effort expectancy positively as well as significantly affect the behavioral intention of the users. Accordingly, the users feel comfortable using e-flipped learning. This result is consistent with these studies (Al-Khatib, Lee, Suh, \& Weerakkody, 2019; Davis et al., 1989; Gupta, Dasgupta, \& Gupta, 2008; Nahla Aljojo, 2020). Third, the results revealed that there is a positive and significant effect of social influence on the behavioral intention of the users to use e-flipped learning; this result is confirmed by these studies (Camilleri, 2019; Zhou et al., 2019). Finally, the result of this study indicated that there is also a positive and significant effect of system characteristic on the behavioral intention of the users to use e-flipped learning; this result is consistent in these studies (Al-Rahmi et al., 2019; Pituch \& Lee, 2006).

These factors: social influence, performance expectancy, effort expectancy, and system characteristics had a significant contribution on the behavioural intention in the suggested e-flipped learning 
acceptance model. Accordingly, the results are demonstrated the appropriateness of the suggested E-flipped learning model for enhancing the students' educational achievements in Jordan.

\section{CONCLUSION}

This descriptive study used a quantitative survey method, and the methodology employed in this study had investigated the effort expectancy, social influence, the factors performance expectancy and system characteristics and their effects on students' e-flipped learning usage. Therefore, the implementation of Eflipped learning system had a valuable effect on enhancing the learning process in Jordan. As well as, the UTAUT model had been modified by adding system characteristics for introducing a new model to measure the students' acceptance of E-flipped learning in Jordan.

Accordingly, this model can help the system designers and the web designers to use certain features like reminders, chatting, YouTube and a group discussion to e-flipped learning. While, the means and population for obtaining a representative sample is explained in the data collection. Moreover, to investigate the difficulties that were faced by user acceptance of E-flipped learning for students in Jordan.

\section{REFERENCES}

Ahmed, Hanaa Ouda Khadri. (2016). Flipped learning as a new educational paradigm: An analytical critical study. European Scientific Journal, 12(10).

Al-Okaily, Manaf, Lutfi, Abdalwali, Alsaad, Abdallah, Taamneh, Abdallah, \& Alsyouf, Adi. (2020). The determinants of digital payment systems' acceptance under cultural orientation differences: The case of uncertainty avoidance. Technology in Society, 63, 101367.

Al-Rahmi, Waleed Mugahed, Alias, Norma, Othman, Mohd Shahizan, Alzahrani, Ahmed Ibrahim, Alfarraj, Osama, Saged, Ali Ali, \& Rahman, Nur Shamsiah Abdul. (2018). Use of e-learning by university students in Malaysian higher educational institutions: a case in Universiti Teknologi Malaysia. Ieee Access, 6, 14268-14276.

Alawamreh, Ali Ratib, \& Elias, Nur Fazidah. (2015). Examining The Effectiveness of Using Web-Based Learning for Gifted Students: Jordan as Case Study. Journal of Theoretical \& Applied Information Technology, 76(2).

Alawamreh, Ali Ratib, \& Elias, Nur Fazidah. (2016). The Acceptance of e-Learning System for Gifted Students in Developing Country (Jordan Case Study).

Almajali, Dmaithan Abdelkarim, \& Al-Lozi, Musa. (2016). Determinants of the actual use of e-learning systems: An empirical study on Zarqa University in Jordan. Journal of Social Sciences (COES\&RJ-JSS), $5(2), 172-200$.

Andujar, Alberto, Salaberri-Ramiro, María Sagrario, \& Cruz Martínez, María Soledad. (2020). Integrating flipped foreign language learning through mobile devices: Technology acceptance and flipped learning experience. Sustainability, 12(3), 1110.

Armitage, Christopher J, Norman, Paul, \& Conner, Mark. (2002). Can the theory of planned behaviour mediate the effects of age, gender and multidimensional health locus of control? British journal of health psychology, 7(3), 299-316.

Attuquayefio, Samuel, \& Addo, Hillar. (2014). Using the UTAUT model to analyze students' ICT adoption. International Journal of Education and Development using ICT, 10(3).

Balogun, Julia, Huff, Anne Sigismund, \& Johnson, Phyl. (2003). Three Responses to the Methodological Challenges of Studying Strategizing*. Journal of Management Studies, 40(1), 197-224.

Bergmann, Jonathan, \& Sams, Aaron. (2014). Flipped learning: Gateway to student engagement: International Society for Technology in Education.

Bognar, Branko, Sablić, Marija, \& Škugor, Alma. (2019). Flipped learning and online discussion in higher education teaching Didactics of smart pedagogy (pp. 371-392): Springer.

Brown, Irwin TJ. (2002). Individual and technological factors affecting perceived ease of use of web-based learning technologies in a developing country. The Electronic Journal of Information Systems in Developing Countries, 9.

Catherine, Nyesiga, Geofrey, Kituyi Mayoka, Moya, Musa B, \& Aballo, Grace. (2018). Effort Expectancy, Performance Expectancy, Social Influence and Facilitating Conditions as Predictors of Behavioural 
Intentions to use ATMS with Fingerprint Authentication in Ugandan Banks. Global Journal of Computer Science and Technology.

Cegarra, José Luis Moreno, Navarro, Juan Gabriel Cegarra, \& Pachón, José Rodrigo Córdoba. (2014). Applying the technology acceptance model to a Spanish City Hall. International Journal of Information Management, 34(4), 437-445.

Chen Hsieh, Jun Scott, Wu, Wen-Chi Vivian, \& Marek, Michael W. (2017). Using the flipped classroom to enhance EFL learning. Computer Assisted Language Learning, 30(1-2), 1-21.

Cheok, Mei Lick, Wong, Su Luan, Ayub, Ahmad Fauzi, \& Mahmud, Rosnaini. (2017). Teachers' Perceptions of E-Learning in Malaysian Secondary Schools. Malaysian Online Journal of Educational Technology, $5(2), 20-33$.

Hameed, Farhina, \& Qayyum, Abdul. (2018). Determinants of behavioral intention towards mobile learning in Pakistan: Mediating role of attitude. Business and Economic Review, 10(1), 33-61.

Ifinedo, Princely. (2016). Applying uses and gratifications theory and social influence processes to understand students' pervasive adoption of social networking sites: Perspectives from the Americas. International Journal of Information Management, 36(2), 192-206.

Jalal, Ahmad, \& Mahmood, Maria. (2019). Students' behavior mining in e-learning environment using cognitive processes with information technologies. Education and Information Technologies, 24(5), 2797-2821.

Jong, Din, \& Wang, Tzong-Song. (2009). Student Acceptance of Web-based Learning System. Paper presented at the Proceedings of the 2009 International Symposium on Web Information Systems and Applications (WISA'09), Nanchang, China.

Kelley, Kate, Clark, Belinda, Brown, Vivienne, \& Sitzia, John. (2003). Good practice in the conduct and reporting of survey research. International Journal for Quality in Health Care, 15(3), 261-266.

Kim, Sung-Wan, \& Seo, B. (2009). The Development of e-Learning Platform for Gifted Children Education. Published on International Journal for Educational Media and Technology, 3(1), 39-51.

King, Chula, \& Piotrowski, Chris. (2015). E-Learning and Flipped Instruction Integration in Business Education: A Proposed Pedagogical Model. Journal of Instructional Pedagogies, 16.

Krejcie, Morgan , \& Morgan, Daryle W. (1970). Determining sample size for research activities. Educational and psychological measurement, 30(3), 607-610.

Leavy, Patricia. (2017). Research design: Quantitative, qualitative, mixed methods, arts-based, and community-based participatory research approaches: Guilford Publications.

Nikou, Stavros A, \& Economides, Anastasios A. (2017). Mobile-based assessment: Investigating the factors that influence behavioral intention to use. Computers \& Education, 109, 56-73.

Nunnally, Jum C. (1978). Psychometric Theory 2nd ed: Mcgraw hill book company.

Preston, Carolyn C, \& Colman, Andrew M. (2000). Optimal number of response categories in rating scales: reliability, validity, discriminating power, and respondent preferences. Acta psychologica, 104(1), 115.

Razak, Fahmi Zaidi Bin Abdul, Bakar, Azlina Abu, \& Abdullah, Wan Salihin Wong. (2017). How perceived effort expectancy and social influence affects the continuance of intention to use e-government. A study of a Malaysian government service. Electronic Government, an International Journal, 13(1), 69-80.

Sargent, Julia, \& Casey, Ashley. (2020). Flipped learning, pedagogy and digital technology: Establishing consistent practice to optimise lesson time. European Physical Education Review, 26(1), 70-84.

Schaper, Louise K, \& Pervan, Graham. (2009). A Model of Information and Communications Technology Accpetance and Utilisation by Occupational Therapists: Citeseer.

Shroff, Ronnie H, Vogel, Doug, Coombes, John, \& Lee, Fion. (2007). Student E-Learning Intrinsic Motivation: A Qualitative Analysis. Communications of the Association for Information Systems, 19.

Taylor, Shirley, \& Todd, Peter. (1995). Decomposition and crossover effects in the theory of planned behavior: A study of consumer adoption intentions. International journal of research in marketing, 12(2), 137155.

Thomas, Troy, Singh, Lenandlar, \& Renville, Dwayne. (2020). The Utility of the UTAUT: An Application to Mobile Learning Adoption in the Caribbean. International Journal of Education and Development using Information and Communication Technology, 16(2), 122-143.

Venkatesh, Viswanath, Morris, Michael G, Davis, Gordon B, \& Davis, Fred D. (2003). User acceptance of information technology: Toward a unified view. MIS quarterly, 425-478. 
Vululleh, Pee. (2018). Determinants of students'e-learning acceptance in developing countries: An approach based on Structural Equation Modeling (SEM). International Journal of Education and Development using ICT, 14(1).

Wong, Kenneth, Wang, Fu Lee, Ng, Kwan Keung, \& Kwan, Reggie. (2015). Investigating acceptance towards mobile learning in higher education students Technology in Education. Transforming Educational Practices with Technology (pp. 9-19): Springer.

Yeo, Vincent Cheow Sern, Goh, See-Kwong, \& Rezaei, Sajad. (2017). Consumer experiences, attitude and behavioral intention toward online food delivery (OFD) services. Journal of Retailing and Consumer Services, 35, 150-162.

Zainuddin, Zamzami. (2018). Students' learning performance and perceived motivation in gamified flippedclass instruction. Computers \& education, 126, 75-88. 